Www.jmscr.igmpublication.org

Index Copernicus Value: 79.54

ISSN (e)-2347-176x ISSN (p) 2455-0450

crossref DOI: https://dx.doi.org/10.18535/jmscr/v7i6.04

Original Research Article

\title{
A Cross Sectional Study of clinical and Electrocardiographic profile in Chronic Obstructive Pulmonary Disease Patients and Its co-relation with the Severity of Disease
}

\author{
Authors \\ Dr Lokesh Verma ${ }^{1}$, Dr Sanidhaya Tak ${ }^{2 *}$, Dr Govind Desai ${ }^{3}$, Dr Neetu Maurya ${ }^{4}$ \\ ${ }^{1}$ Post Graduate Student, Department of Pulmonary Medicine Dr S.N Medical College, Jodhpur, Rajasthan, \\ India \\ ${ }^{2}$ Senior Resident, Department of Pulmonary Medicine, AIIMS Jodhpur, Rajasthan, India \\ ${ }^{3}$ Post-Graduate Student, Department of Pulmonary Medicine Dr S.N Medical College, Jodhpur, Rajasthan, \\ India \\ ${ }^{4}$ Post-Graduate Student, Department of Anesthesia Dr S.N Medical College, Jodhpur, Rajasthan, India \\ *Corresponding Author \\ Dr Sanidhaya Tak \\ Senior Resident, Department of Pulmonary Medicine, AIIMS Jodhpur, Rajasthan, India
}

\begin{abstract}
Background: COPD is associated with significant extra pulmonary (systemic) effects among which cardiovascular disease are most common. COPD is the $4^{\text {th }}$ leading cause of death worldwide. Early diagnoses and intervention for cardiac comorbidities would reduce mortalities in COPD patients. Electrocardiography (ECG) give information about cardiac disease and severity and prognosis in COPD patients.

Methodology: It is a cross-sectional descriptive type of study conducted in 69 patients of stable COPD in the department of pulmonary medicine, Kamla Nehru Chest Hospital, Jodhpur. They were staged by Pulmonary function test (PFT) and evaluated by electrocardiography.

Results: Mean age was 58.52 10.02 years, with male preponderance, male to female ratio7:3. Mean

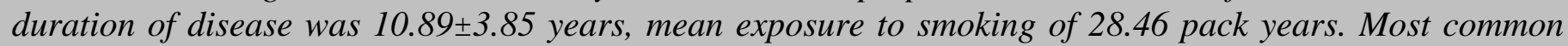
ECG finding was RVH which was present in 55.07\% of cases, other ECG findings are P. pulmonale (30.43\%), low voltage complex (50.72\%), RAD (39.13\%), poor $R$ wave progression (27.53\%). All ECG findings significantly correlated with disease severity (' $p$ ' value $<0.05$ )

Conclusion: Diagnostic values of ECG among patients with respiratory problems suggest that COPD patients should be screened electrocardiographically in addition to other clinical investigations. COPD is more common in male in 5th to 7th decade of life, with a smoking history of more than 30 pack years. The occurrence of ECG findings increase as severity and duration of disease increase. It can be inferred that ECG is a useful bedside test to assess the severity of COPD.

Keywords: Chronic obstructive pulmonary disease (COPD), Electrocardiography (ECG).
\end{abstract}




\section{Introduction}

COPD includes emphysema and chronic bronchitis, Emphysema is an anatomically destruction and enlargement of lung alveoli and Chronic bronchitis is defined as chronic productive cough for continuous three months for consecutive two years. ${ }^{1}$ COPD is currently the fourth leading cause of death in world, but is projected to be the $3^{\text {rd }}$ leading cause of death by 2020.,3 Chronic Obstructive Pulmonary Disease (COPD) is a common, preventable and treatable disease that is characterized by persistent respiratory symptoms and airflow limitation that is due to airway and/or alveolar abnormalities usually caused by significant exposure to noxious particles or gases. ${ }^{4}$

COPD is associated with significant extra pulmonary (systemic) effects among which cardiac manifestations are most common. Cardiovascular disease accounts for approximately $50 \%$ of all hospitalization and nearly on third of all deaths, if forced expiratory volume in one second $\left(\mathrm{FEV}_{1}\right)>50 \%$ of predicted. ${ }^{5}$ In more advanced disease cardiovascular disease account for $20 \%-25 \%$ of all deaths in COPD. ${ }^{5}$ COPD affects pulmonary blood vessels, right ventricle, as well as left ventricle leading to development of pulmonary hypertension, corpulmonale, right ventricular dysfunction, and left ventricular dysfunction too.

Electrocardiography is a rapid, widely available non-invasive method to assess the cardiac function in patients with COPD.

Electrocardiogram is a very simple and convenient bedside investigation, it would be great importance, if it can be established that a high degree of correlation between ECG and different grades of disease is present which indicates the severity of COPD.

Our study was undertaken with the following aims and objectives:

1. To assess the cardiac changes secondary to COPD by electrocardiography (ECG).

2. To find out the correlation between electrocardiographic(ECG) findings and the severity of COPD using GOLD 2018 guidelines

\section{Materials and Methods}

A cross sectional descriptive type study was conducted in Kamla Nehru Chest Hospital, Dr S N Medical College Jodhpur, a tertiary care center for respiratory diseases in western part of Rajasthan, India. 69 COPD patients were enrolled for the study who were diagnosed by performing Spirometry and Chest X-ray. During the selection, Patients with pulmonary thromboembolism, obstructive sleep apnea, Previously known/ diagnosed primary cardiac disease, Chronic lung disease other than COPD such as bronchiectasis, asthma, old pulmonary TB, interstitial lung diseases, lung cancer, silicosis etc. Other Systemic diseases which may have pulmonary and cardiac manifestations (CVD, portal hypertension, drugs, toxins, pulmonary veno-occlusive disease etc.) were excluded from the study.

All of 69 patients were investigated by spirometry and diagnosed and classified according to GOLD guidelines 2018 (post bronchodilator $\mathrm{FEV}_{1} /$ forced vital capacity (FVC) ratio $<70 \%$ predicted), mild (FEV ${ }_{1} \geq 80 \%$ of predicted), moderate $\left(50 \% \leq \mathrm{FEV}_{1}<80 \%\right.$ predicted $)$, severe $\left(30 \% \leq \mathrm{FEV}_{1}<50 \%\right.$ predicted $)$, and very severe (FEV ${ }_{1}<30 \%$ predicted), respectively. ${ }^{4}$

All statistical analyses were performed by using SPSS 22.0 software package (SPSSInc Chicago, IL, USA). Yates continuity correction test *(Chi square test), Fisher's exact test and Fisher--Freeman---Halton test were used for comparison of qualitative data. All data were summarized as mean \pm SD for continuous variables, numbers and percentages for categorical variables.A $p$ value of $<0.05$ was accepted as statistically significant.

\section{Electrocardiography (ECG)}

Several studies have reported ECG changes like rightward displacement of QRS axis, changes in P-wave axis and amplitude, reduction in the amplitude of QRS complex, sinus tachycardia, right bundle branch block (RBBB) and right 
ventricular hypertrophy in patients with $\mathrm{COPD}^{\mathbf{6 - 9}}$. $\mathrm{P}$-pulmonale has been used as an indirect evidence of RVH by many authors S. Padmawati and Raizada $^{10}$. Its occurrence must be largely attributed to positional, partly to haremodynamic changes, but it cannot be designated as an unequivocal criterion of RVH.

Right axis deviation of QRS has been suggested as a sign of $\mathrm{RVH}$ and dilatation. It showed a relation to RV thickness and to increase in pulmonary artery pressure ${ }^{10}$.

ECG criteria for right for right ventricular hypertrophy $^{11}$ :

1. Right axis deviation of QRS complex

2. P-pulmonale

3. $\mathrm{R}<\mathrm{S}$ inV6

4. $A+R-P L \geq 0.7$; where $A=$ maximal $R / R$ ' amplitude in V1orV2, $\mathrm{R}=$ maximal $\mathrm{S}$ in lead I or $\mathrm{V} 6, \mathrm{PL}=$ minimal $\mathrm{S}$ in $\mathrm{V} 1$ or minimal $\mathrm{R}$ in lead I or V6.

ECG criteria for corpulmonale ${ }^{\mathbf{1 2}}$

1. Right axis deviation of QRS complex

2. P-pulmonale

3. Right bundle branch block (incomplete) with $\mathrm{rSR}$ in right precordiall leads with QRS duration $>0.12$ seconds

4. $\mathrm{R} / \mathrm{S}$ ratio in $\mathrm{V} 1>1$. Dominant ' $\mathrm{R}$ ' wave in right precordial leads

5. $\mathrm{R} / \mathrm{S}$ ratio in $\mathrm{V} 6<1$. $\mathrm{R}$-wave in $\mathrm{V} 6 \leq 0.5 \mathrm{mV}$ or $\mathrm{R} / \mathrm{S}$ ratio in $\mathrm{V} 6<1$ points towards $\mathrm{RVH}$.

The detection of RV hypertrophy in ECG has a high specificity but very low sensitivity. A normal ECG does not exclude the presence of pulmonary hypertension in COPD30. Scott et al'reported that right ventricular hypertrophy was present on the electrocardiogram in $29 \%$ with severe chronic obstructive pulmonary disease.

Inversion of ' $\mathrm{T}$ ' wave in right leads has been explained on the basis of RV dilation and strain. Generalised $T$ wave inversion may be a nonspecific phenomenon related to hypoxia.

\section{Results}

The present study is done with 69 individuals diagnosed to have COPD by using spirometry.
Table 1: Age wise distribution of cases $(n=69)$

\begin{tabular}{|l|c|c|}
\hline Age (in years) & No. of Cases & Percentage \\
\hline $35-40$ & 03 & 4.34 \\
\hline $40-50$ & 13 & 18.85 \\
\hline $50-60$ & 21 & 30.43 \\
\hline $60-70$ & 27 & 39.13 \\
\hline$>70$ & 05 & 7.24 \\
\hline Total & 69 & $100 \%$ \\
\hline Mean age \pm SD & $58.52 \pm 10.02$ & \\
\hline
\end{tabular}

Table 2: Sex Distribution of cases $(n=69)$

\begin{tabular}{|l|c|c|c|}
\hline Sex & No. of Cases & Percentage & Mean \pm SD \\
\hline Male & 49 & 71.01 & $59.70 \pm 10.58$ \\
\hline Female & 20 & 28.99 & $55.65 \pm 8.00$ \\
\hline Total & 69 & 100 & $\mathrm{P}=0.445$ \\
\hline
\end{tabular}

Table 3: Total duration of Illness $(n=69)$

\begin{tabular}{|l|c|c|}
\hline Duration (in years) & No. of Cases & Percentage \\
\hline$<10$ & 56 & 81.15 \\
\hline$\geq 10$ & 13 & 18.85 \\
\hline Total & 69 & $100 \%$ \\
\hline
\end{tabular}

Table 4: No. of Pack years in COPD patients

\begin{tabular}{|l|c|c|}
\hline Pack years & No. of Cases & Percentage \\
\hline $15-30$ & 14 & 28.60 \\
\hline$>30$ & 35 & 71.40 \\
\hline Total & 49 & $100 \%$ \\
\hline
\end{tabular}

Table 5: Clinical signs of Cor pulmonale in COPD Patients

\begin{tabular}{|l|c|c|}
\hline Cor pulmonale & No. of Cases & Percentage \\
\hline Yes & 19 & 27.53 \\
\hline No & 50 & 72.46 \\
\hline Total & 69 & $100 \%$ \\
\hline
\end{tabular}

Table 6: Severity of COPD according to GOLD classification 2018

\begin{tabular}{|l|c|c|}
\hline GOLD Std. criteria & No. of COPD Patients & Percentage \\
\hline Mild & 04 & 5.80 \\
\hline Moderate & 24 & 34.78 \\
\hline Severe & 25 & 36.23 \\
\hline V. severe & 16 & 23.18 \\
\hline
\end{tabular}

Table 7: ECG Findings in COPD Patients

\begin{tabular}{|l|c|c|}
\hline ECG Parameter & $\begin{array}{c}\text { No. of } \\
\text { patients }\end{array}$ & $\begin{array}{c}\text { Percentage } \\
\text { (\%) }\end{array}$ \\
\hline P- Pulmonale & 21 & 30.43 \\
\hline Low voltage complex & 35 & 50.72 \\
\hline Poor R wave progression & 19 & 27.53 \\
\hline Right axis deviation & 27 & 39.13 \\
\hline $\begin{array}{l}\text { RVH ( right ventricular } \\
\text { hypertrophy) }\end{array}$ & 38 & 55.07 \\
\hline
\end{tabular}




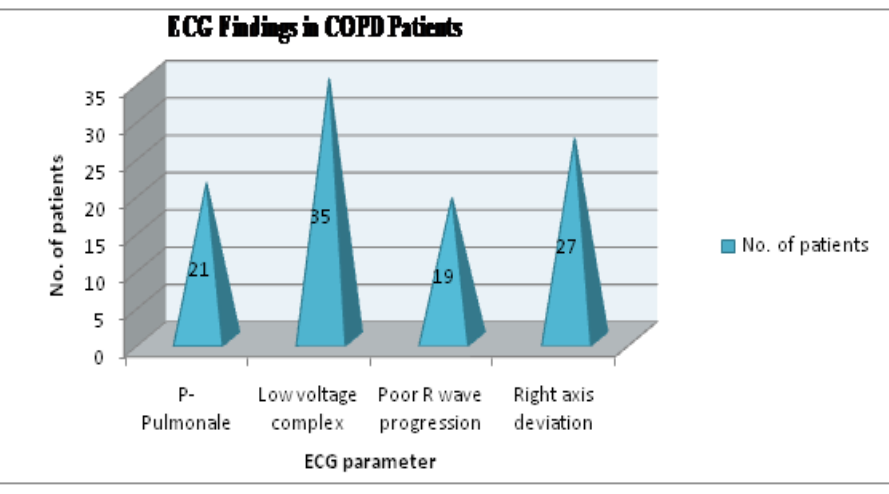

Table 8 ECG changes with disease severity of COPD

\begin{tabular}{|l|c|c|}
\hline COPD stages & $\begin{array}{c}\text { No. of patients } \\
\text { ECG changes }\end{array}$ & Percentage \\
\hline Mild (4) & 1 & $25 \%$ \\
\hline Moderate (24) & 10 & $41.66 \%$ \\
\hline Severe (25) & 12 & $48 \%$ \\
\hline Very severe (16) & 15 & $93.75 \%$ \\
\hline
\end{tabular}

Table 10: Comparison of ECG finding with other study

\begin{tabular}{|l|c|c|c|c|}
\hline ECG findings & $\begin{array}{c}\text { P } \\
\text { pulmonale }\end{array}$ & $\begin{array}{c}\text { Poor R } \\
\text { wave } \\
\text { progression }\end{array}$ & RAD & RVH \\
\hline Shekhar et al & $48 \%$ & $32 \%$ & $64 \%$ & $56 \%$ \\
\hline Jatav et al & $45 \%$ & $35 \%$ & $69 \%$ & $53 \%$ \\
\hline Present study & $30.43 \%$ & $27.53 \%$ & $39.13 \%$ & $55.07 \%$ \\
\hline
\end{tabular}

Table 9: Electrocardiographic changes in COPD patient

\begin{tabular}{|l|c|c|c|c|c|}
\hline $\begin{array}{l}\text { ECG } \\
\text { Findings }\end{array}$ & $\begin{array}{c}\text { GOLD } \\
\mathbf{1} \\
\text { Mild } \\
(\mathbf{n = 4})\end{array}$ & $\begin{array}{c}\text { GOLD } \\
\text { 2Moder } \\
\text { ate } \\
(\mathbf{n = 2 4})\end{array}$ & $\begin{array}{c}\text { GOLD 3 } \\
\text { Severe } \\
(\mathbf{n = 2 5})\end{array}$ & $\begin{array}{c}\text { GOLD4 } \\
\text { V. } \\
\text { Severe } \\
(\mathbf{n = 1 6 )}\end{array}$ & $\begin{array}{c}\text { P } \\
\text { Valu } \\
\mathbf{e}\end{array}$ \\
\hline $\begin{array}{l}\text { P } \\
\text { Pulmonale }\end{array}$ & 00 & $\begin{array}{c}04 \\
(16.6 \%)\end{array}$ & $\begin{array}{c}06 \\
(24 \%)\end{array}$ & $\begin{array}{c}11 \\
(68.7 \%)\end{array}$ & 0.013 \\
\hline $\begin{array}{l}\text { Low } \\
\text { voltage } \\
\text { complex }\end{array}$ & 00 & 08 & 12 & 15 & 0.035 \\
$(33.3 \%)$ & $(48 \%)$ & $(93.7 \%)$ & \\
\hline $\begin{array}{l}\text { Poor R } \\
\text { wave } \\
\text { progression }\end{array}$ & 00 & $\begin{array}{c}03 \\
(12.5 \%)\end{array}$ & $\begin{array}{c}06 \\
(24 \%)\end{array}$ & $\begin{array}{c}10 \\
(62.5 \%)\end{array}$ & 0.04 \\
\hline $\begin{array}{l}\text { Right axis } \\
\text { deviation }\end{array}$ & 01 & 06 & 08 & 12 & 0.012 \\
\hline RVH & 02 & 10 & 12 & 14 & 0.001 \\
$(50 \%)$ & $(41.6 \%)$ & $(48 \%)$ & $(87.5 \%)$ & \\
\hline
\end{tabular}

\section{Discussion}

A total of 76 patients were enrolled for study of which 69 subjects fulfilled inclusion criteria and were included in study after written and informed consent. All the included subjects were evaluated by electrocardiogram (ECG) to screen cardiac changes secondary to COPD. COPD often exists with comorbidities that may have a significant impact on prognosis ${ }^{14}$

Some of these arise independently of COPD whereas others may be causally related, either with shared risk factors or by one disease actually increasing the risk of another. It is possible that features of COPD, such as systemic inflammation are shared with other diseases as such this mechanism represent a link between COPD and some of its co morbidities

Maximum number of patients were in 51-70 years of age group (69.56\%). Mean age was $58.52 \pm 10.02$ years similar age pattern was seen in earlier studies like H. S. Trivedi et al who report age group 48 to 70 years (mean 59.5 \pm 4.92 ). ${ }^{\mathbf{1 3}}$, Oswald-Mammosser et $\mathrm{al}^{\mathbf{1 4}}$. (Table 1)

Majority of study subjects were males (71.01\%). This was probably because of the fact that majority of our male patients were smokers. (Table 2)

$71 \%$ of patients were smokers with a smoking history of 15-60 pack years, emphasizing the fact that tobacco smoking is the most potent risk factor resulting in development of COPD. $29 \%$ of patients were nonsmoker had bio fuel mass exposer and indoor air pollution also contributes development of COPD. Majority of smokers 35 $(71.40 \%)$ had > 30 pack years and $14(28.60 \%)$ had 15-30 pack years. Similar results reported by Jindal S K et al.2001 ${ }^{\mathbf{1 5}}$, Jindal S K et al.2006 ${ }^{\mathbf{1 6}}$. (Table 3)

19 patients $(27.53 \%)$ had clinical signs of cor pulmonale. Signs of cor pulmonale are present in most of the severe group of COPD patients. Study by Gupta and khastgir et al ${ }^{17}$ suggested that their study population comprised mainly of severe COPD.( Table 4)

The mean duration of illness was $8.1 \pm 5.6$ years. Maximum no. of patients $56(81.15 \%)$ had symptoms for less than 10 years and $13(18.85 \%)$ of the patients had symptoms $\geq 10$ years. In a study by Gupta et $\mathrm{al}^{\mathbf{1 8}}$, the mean duration of symptoms was $8.9 \pm 4.9$ years. (Table 5 )

Our study concluded that the frequency of Mild, Moderate, Severe and Very severe disease was 
$5.8 \%, 34.78 \%, 36.23 \%$ and $23.18 \%$ respectively. According to GOLD stage of severity, majority (71\% patients) of patients were suffering from moderate to severe COPD, highlighting the fact that COPD patients often seek medical care late, when they become breathless on exertion. (Table 6)

The study was observed that ECG changes were more suggestive of $\mathrm{PH}$ in very severe COPD patients as compared to mild COPD where ECG was not suggestive of $\mathrm{PH}$ in most of the patients. The ECG findings was seen in Right ventricular hypertrophy (RVH), P-pulmonale, and right axis deviation in the patients $55.07 \%, 30.43 \%$, and 39.13 respectively. low voltage complex, poor $\mathrm{R}$ wave progression, the ECG characteristic of emphysema, was observed in $50.72 \%$ \& $27.53 \%$ respectively. These findings correlate with that of Padmawathi and Raizada et al ${ }^{10}$. (Table 7)

In mild category $25 \%$ had ECG changes, in moderate category $41.66 \%$, in severe category 48 $\%$, in very severe category $93.75 \%$ had ECG changes (Table 8). Similar results seen in Padmawathi and Raizada et al $^{9}$, Shekhar et al ${ }^{19}$ and Jatav et al ${ }^{\mathbf{2 0}}$.

In mild category COPD patients there is no ECG finding except RAD and $\mathrm{RVH}$, which was present in 1 out of 4 patients $(25 \%)$ and 2 out of 4 patients (50\%). RVH was observed in $50 \%$ in mild category patients while in case of moderate, severe and very severe it was seen in $41.6 \%, 48 \%$, and $87.5 \%$ cases respectively. P. Pulmonale was observed in $0 \%$ in mild category patients while in case of moderate, severe and very severe it was seen in $16.6 \%, 24 \%$ and $68.7 \%$ respectively. RAD was observed in $25 \%$ of mild category patients while in case of moderate, severe and very severe it was seen in $25 \%, 32 \%$ and $75 \%$ respectively. Poor $\mathrm{R}$ wave progression was observed in $0 \%$ in mild category patients while in case of moderate, severe and very severe it was seen in $12.5 \%, 24 \%$ and $62.5 \%$ respectively. Similar results seen in Padmawathi and Raizada et al ${ }^{9}$, Shekhar et al 19 and Jatav et al ${ }^{20}$.(Table 9)

\section{Conclusion}

In clinical practice, cases having respiratory problems especially COPD should also be assessed for ECG changes and our decision should be supplemented by those findings. The most common ECG findings in COPD were RAD, $\mathrm{RVH}$ and $\mathrm{P}$ Pulmonale. ECG changes significantly correlated with disease severity. It can be inferred that ECG is a useful bedside test to assess the severity of COPD when spirometry is not available. In view of the very significant correlation of disease severity with the increasing incidence of electrocardiographic abnormalities, a more aggressive approach to treat the COPD patients can be taken so that the onset of Corpulmonale would be delayed as long as possible.

Funding: No funding sources

Conflict of interest: None declared

Ethical approval: The study was approved by the institutional ethics committee

\section{References}

1. Reilly J, Silverman. chronic obstructive pulmonary disease. In: Kasper Dennis, Hauser Stephen, Jameson J. Larry, S. Fauci anthony, Longo, Loscalzo. Harrison's principles of internal medicine 19th edition, from New York, NY: McGraw Hill; 2015:2:1700.

2. Murray CJL, Lopez AD (1997) Alternative projections of mortality and disability by cause 1990-2020: Global Burden of Disease Study. Lancet 349: 1498-1504

3. Chen JC, Mannino DM. Worldwide epidemiology of chronic obstructive pulmonary disease. Curr Opin Pulm Med.1990- 2020;5:93-9.

4. Global initiative for chronic obstructive lung disease: global strategy for the diagnosis, management and prevention of chronic obstructive disease, Report;2018

5. Anthonisen N, Connett JE, Kiley JP, Altose MD, Bailey WC, et al. Effects of Smoking 
Intervention and the Use of an Inhaled Anticholinergic Bronchodilator on the Rate of Decline of FEV1. JAMA. 1994;272: 1497-1505.

6. Calatayud JB, Abad JM, Khoi NB et al. Pwave changes in chronic obstructive pulmonary disease. Am Heart J 1970; 79:444.

7. Scott RC. The electrocardiogram in pulmonary emphysema and chronic corpulmonale. Am Heart J 1961; 61:843.

8. Spodick DH, Hauger-Kelvene JH, Tyler. JM. Meusch H. Dott CA. The electrocardiogram in pulmonary emphysema. Relationship of characteristic electrocardiographic findings to the severity of disease measured by degree of airflow obstruction. Am Rev Resp Dis 1963; 88:14.

9. Scott RC, Kaplan S, Fowler NO, Helm RA, Westcott RN, Walker IC, Stiles WJ. The electrocardiographic pattern of right ventricular hypertrophy in chronic cor pulmonale. Circulation. 1955; 11:927-936.

10. S.Padmavati \& Veena Raizada .Electrocardiogram in Chronic corpulmonale. British Heart Jounal 1972;34;658-667

11. Lehtonen J, Sutinen S. Ikaheimo M, Paakko $\mathrm{P}$ Elecrocardiographic criteria for the diagnosis of right ventricular hypertrophy verified at autopsy. Chest 1988;93;839-42

12. John H Philips, George H Burch. Problems in the diagnosis of corpulmonale. Am Heart J 1963;6(6);818-832

13. HS Trivedi, MN Joshi, AR Gamade: Echocardiography and pulmonary artery pressure: correlation in chronic obstructive pulmonary disease Year: 1992 | Volume : 38 | Issue : 1 | Page : 24-6

14. Oswald-Mammosser M, Oswald T, Nyankiye E, et al. Non-invasive diagnosis of pulmonary hypertension in chronic obstructive pulmonary disease. Comparison of ECG, radiological measurements, echocardiography and myocardial scintigraphy. Eur J Respir Dis.1987;71:419_ 29

15. Jindal SK, Aggarwal AN, Gupta D. A review of population studies from India to estimate the national burden of chronic obstructive pulmonary disease and its associa tion with smoking. Indian $\mathrm{J}$ Chest Dis Allied Sci 2001; 43:139-47

16. S.K. Jindal, A.N. Aggarwal1, K. Chaudhry, S.K. Chhabra, G.A. D’Souza, D. Gupta, S.K. Katiyar et al, R. Kumar, B. Shah and V.K. Vijayan. A Multicentric Study on Epidemiology of Chronic Obstructive Pulmonary Disease and its Relationship with Tobacco Smoking and Environmental Tobacco Smoke Exposure .Indian J Chest Dis Allied Sci 2006; 48: 23-29.

17. Gupta S, Khastgir T,Guota MP, Sethi KK, Manoharan S. clinical, hemodynamic and elctrocardiographic study in chronic cor pilmonale, JAPI 1989;(6);373-376.

18. NK Gupta, Ritesh Kumar Agrawal, AB Srivastav, and ML Ved. Echocardiographic evaluation of heart in chronic obstructive pulmonary disease patient and its corelation with the severity of disease. Lung India. 2011 Apr-Jun; 28(2): 105-109.

19. Sekhar CG. Study of cardiovascular complications in chronic obstructive pulmonary disease with reference to ECG and 2D echocardiography findings. American J Pharmacy Health Research 2016;4(01). ISSN:2321-3647.

20. Jatav VS, Meena SR, Jelia S, Jain P, Ajmera D, Agarwal V, Dayma CL, Arif $M$. Electrocardiographic characteristics of patients with chronic obstructive pulmonary disease and its correlation with disease severity. Int J Adv Med 2017;4:514-8. 